\title{
DAS MÚLTIPLAS FACES DA INTENÇÃO REALISTA
}

\author{
Maria Nazareth Soares Fonseca* \\ Karina de Almeida Calado** \\ Roberta Maia Ferreira Alves***
}

* Pontifícia Universidade Católica de Minas Gerais (PUC Minas). Docente do Programa de Pós-Graduação em Letras da PUC Minas - Pesquisadora CNPq.

** Pontifícia Universidade Católica de Minas Gerais (PUC Minas). Mestre em Literaturas de Língua portuguesa. Doutoranda do Programa de Pós-Graduação em Letras da PUC Minas.

*** Universidade dos Vales do Jequitinhonha e Mucuri (UFVJM). Doutora em Literaturas de Língua Portuguesa pela PUC Minas. Docente do Bacharelado em Ciência e Tecnologia do Instituto e Tecnologia da UFVJM. 
O minissimpósio "Realismos, deslocamentos e memórias", realizado em maio de 2017, na PUC Minas, com a coordenação das pesquisadoras Karina Calado e Roberta Alves, procurou retomar discussões que, desde 2010, vêm sendo produzidas pelo Grupo de Pesquisa "Estéticas Diaspóricas"(GEED) com o objetivo de avaliar, criticamente, as diferentes vertentes e feições de uma "intenção realista" que, como salienta Pellegrini (2012), está presente na literatura desde suas origens, bem antes, portanto, de se configurar como uma expressão estética, "de lastro francamente positivista", no final do século XIX.

$\mathrm{Na}$ esfera da literatura, as várias roupagens assumidas pela "intenção realista", ao longo do século XX, vêm instigando reflexões sobre o anseio de ser elaborada "uma representação exata, objetiva e total da realidade" (PELLEGRINI, 2012), questão que considera tanto o apelo ao "realismo da exterioridade" (FIGUEIREDO, 2012, p. 120) quanto a demanda de "tornar a literatura 'real', de criar efeitos de realidade" (SCHØLLHAMMER, 2007, p. 135). No âmbito dessa discussão, várias feições da "intenção realista" foram sendo revistas e analisadas pelos integrantes do GEED, sobretudo as que se relacionam com posturas e posições teóricas surgidas no contexto das literaturas africanas de língua portuguesa quanto às noções de "realismo mágico", "real maravilhoso" e "realismo animista", essa última trazida à discussão, num primeiro momento, por meio dos personagens do romance Lueji (1989), do escritor angolano Pepetela. Embora o escritor angolano tenha usado a expressão sem maiores explicações e com clara intenção irônica, a noção de realismo animista passou a ser utilizada como um operador teórico pertinente para a análise de textos das literaturas africanas, ainda que lhe faltasse uma discussão mais elaborada sobre sua natureza e lógica.

Em cena do romance de Pepetela, a expressão realismo animista é referida como possibilidade de se valer de uma expressão mais afeita à realidade cultural africana e também como resistência à importação pura e simples de termos e teorias nascidas em contextos externos ao continente. É importante ressaltar que, se se considerarem os sentidos construídos pelos diálogos que compõem a cena em que a expressão é mencionada no romance de Pepetela, é possível dizer que ela, de algum modo, se aproximaria dos sentidos dados pelo escritor cubano Alejo Carpentier ao "real maravilhoso", quando pretendeu, com a expressão, alcançar uma forma mais eficaz de nomear feições da cultura hispano-americana. Mais tarde o escritor cubano afirmaria ser o real maravilhoso uma propriedade de qualquer cultura porque expressaria uma forma de percepção singular da natureza em que a magia, o encantamento, o maravilhoso estavam presentes ${ }^{4}$.

No famoso prólogo do romance El reino de este mundo (1948), o escritor cubano referese ao impacto que lhe causaram as ruínas de construções fabulosas erigidas no reinado de Henry Christophe (1787- 1820), no Haiti, e ao fato de que, ao entrar em contato com as ruínas, sentiu-se diante de uma realidade em que o maravilhoso se mostrava de forma concreta, exibindo sua potencialidade como expressão de uma cultura heterogênea, cujos traços se eternizavam nos escombros da Cidadela La Ferrière e do Palácio de Sans-Souci. As palavras de espanto e admiração proferidas pelo escritor cubano sobre as ruínas haitianas embasam sua explicação do que passaria a ser denominado de real maravilhoso e demarcada, na expressão, a sua significação ontológica. Para Carpentier, o real maravilhoso deveria ser entendido como

4 A proposição de Carpentier é discutida por Chiampi (1980, p. 33), que afirma poder ser o real maravilhoso avaliado em dois níveis: "um constituído pelo modo de percepção do real pelo sujeito; outro, pela relação entre a obra narrativa e os constituintes maravilhosos da realidade americana". 
expressão das metamorfoses e simbioses próprias de culturas como a haitiana, a hispanoamericana e a latino-americana, todas elas significadas por misturas culturais intensas e, sobretudo, por se constituírem como uma diferença profunda com relação às culturas europeias. A crítica ao surrealismo fica expressa por Carpentier quando se refere a trucos de prestidigitación (CARPENTIER, 1948, p. 5) e formas mecânicas de fabricação de estranhezas, como instrumentos de criação literária legitimados pelo movimento criado por Breton.

Como se pode perceber, a expressão real maravilhoso tem, em Carpentier, uma intenção fundacional, uma vez que procura ressaltar aspectos culturais e expressões artísticas como as do pintor cubano Wifredo Lam (1902 - 1982), em cujos quadros a natureza americana era captada em sua magia. O real maravilhoso seria, para Carpentier, um signo da cultura americana que, por sua complexidade, marcaria "a renovação da linguagem ficcional hispanoamericana e a consequente crítica do próprio ato de contar”. (CHIAMPI, 1980, p. 72).

As complexidades inerentes a culturas compósitas, como a hispano-americana, indicadas por simbioses e misturas entre perspectivas realistas e mágicas, são percebidas por Carpentier como signos da diferença inscrita nas ruínas haitianas. Nelas, misturados à "atmósfera creada por Henri Christophe, monarca de increíbles empeños" (CARPENTIER, 1948 p. 9), eternizavam-se vestígios da luta de homens ansiosos por liberdade e os "poderes licantrópicos de Mackandal", o líder de escravos negros que organizou um plano de subversão da ordem instalada pelos colonos franceses de São Domingos (JAMES, 1994, p. 34-35), utilizando os seus conhecimentos sobre plantas capazes de curar e de matar. Não por acaso, ao escrever o romance El reino de este mundo (1948), Carpentier tornaria imortal o ex-escravo negro trazido da Guiné, na África.

O real maravilhoso de Carpentier, em seu sentido ontológico, se aproxima, sem poder ser com ele confundido, do "realismo mágico", tal como foi implantado no cenário literário latino-americano por Arturo Uslar Pietri, em 1948 (PIETRI,1948). Aclimatado em cenários literários, o conceito se afasta dos sentidos que tem nas considerações do crítico alemão Franz Roh sobre tendências pós-impressionistas da pintura alemã do início do século XX, sobretudo em criações como as do pintor alemão Georg Schrimpf (1880-1938). O crítico alemão destaca, na expressão pictórica, denominada por ele de realismo mágico, aspectos de uma volta ao real que, no entanto, se afasta da emotividade e subjetividade dos expressionistas. Um retorno ao real que não obstrui a possibilidade de a arte se enveredar pela "dimensão oculta e mágica do objeto" (SCHØLLHAMMER, 2004, p. 121) e por estratégias que permitiam "representar as coisas concretas e palpáveis, para tornar visível o mistério que ocultam” (CHIAMPI, 1980, p. 21). Deslocando-se do contexto da pintura alemã, o realismo mágico, na América Latina, passa a caracterizar um tipo de narrativa que assume o mágico ${ }^{5}$ como potencialidade de uma "nova atitude do narrador diante do real" (CHIAMPI, 1980, p. 21). Utilizada por críticos literários como operador fecundo para a análise da narrativa latino-americana, a expressão ganha legitimidade, sobretudo após a publicação do romance Cien años de soledad (1967), do colombiano Gabriel García Marques.

5 Irlemar Chiampi $(1982$, p. 20) ressalta a crítica do romance latino-americano nomeado pelo realismo mágico, sem "penetrar nos mecanismos de construção de um outro verossímil" e assumindo o modo de ser "estranho, complexo, muitas vezes esotérico e lúcido" como características do novo romance consagrado a partir da década de 1960. Chiampi afirma que a nova tendência se mostraria, desde a década de 1940, em romances como Yawar fiesta, de José Maria Arguedas, em Ficciones (1944), de Borges, El señor Presidente e Hombres de maiz, de Miguel Angel Astúrias, passando por romances de Alejo Carpentier, como El reino de este mundo (1949) e Los pasos perdidos (1953). 
O romance de García Marques se tornaria, desde a sua publicação, a ilustração das feições legitimadas pelo realismo mágico, em sua feição latino-americana, assim como El reino de este mundo, de Carpentier, com relação ao real maravilhoso. Os dois romances assumiriam, portanto, o que Chiampi ressalta como "dilema de nomeação das coisas americanas" (CHIAMPI, 1980, p. 46), ao mesmo tempo que enfatizariam características próprias de uma realidade cultural formada por fecundos processos de mestiçagens. Assim, se se considera que real maravilhoso e realismo mágico definem particularidades de uma forma de narrar que não estabelece fronteiras rígidas entre realidade e magia, entre natural e sobrenatural, é possível afirmar serem essas particularidades próprias de narrativas literárias que assumem formas de ser do continente latino-americano, porque exibem, sobretudo, a riqueza de seus mitos e de sua religiosidade animista.

No âmbito das literaturas africanas de língua portuguesa, feições do real maravilhoso e do realismo mágico e mesmo do fantástico passam a circular em trabalhos críticos voltados a narrativas em que as demandas da realidade social e cultural são tratadas com base na pulsação forte das tradições animistas. É o que afirma, por exemplo, Inocência Mata ${ }^{6}$, quando considera que "o recurso ao insólito, ao absurdo, ao fantástico", como estratégia de enfrentamento do real, perpassa a obra de escritores africanos, como Boaventura Cardoso, Mia Couto, Pepetela, particularmente em $\mathrm{O}$ desejo de Kianda, e Abdulai Sila, em Mistida, dentre outros.

Em cenários literários em que o insólito e o absurdo integram possibilidades de se nomearem tendências literárias africanas, ressurge a expressão "realismo animista", utilizada pelo escritor angolano Pepetela em cena do seu romance Lueji (o nascimento dum império), publicado em 1989. Na cena do romance, a expressão "realismo animista" é utilizada com intenção irônica tanto na fala da personagem Lueji, quanto na da personagem Jaime, quando afirma querer "fustigar os dogmas" da cultura ocidental (PEPETELA, 1989, p. 451). Na cena ficcional, a expressão surge, sem maiores explicações, talvez para indicar o desejo do escritor de colocar em discussão o modo como a história da rainha Lweji, da Lunda, poderia ser assumida em um espetáculo de dança a ser exibido em África. Inserida no âmbito de uma discussão que avalia modos de percepção e de retomada de dados históricos que se misturam a narrativas míticas, a expressão utilizada por Pepetela ganhou significados conceituais sem que fossem legitimados pelo escritor ou pelo romance. Os sentidos da expressão foram sendo produzidos segundo inferências do que disseram as personagens do romance Lueji com relação a conceitos literários que circulam na África: "o realismo e o neo, o realismo socialista e o fantástico, e outros realismos por aî" (PEPETELA, 1989, p. 452). Na cena romanesca, a expressão realismo animista assume feições críticas à importação de termos e intenções estéticas estrangeiras e, ao mesmo tempo, enfatiza os processos de mesclagens inerentes a qualquer cultura.

A expressão ganhará uma discussão pertinente na reflexão do teórico Harry Garuba, professor da Universidade de Cape Town, África do Sul, sobre manifestações de um inconsciente animista e de uma lógica que subverte binarismos e "desestabiliza a hierarquia da ciência sobre a magia e da narrativa secularista da modernidade através da reabsorção do tempo histórico nas matrizes do mito e do mágico" (GARUBA, 2012, p. 242). Ao defender o ponto de vista de

$\overline{6 \text { As afirmações da }}$ crítica sãotomense integram o texto "O pós-colonial nas literaturas africanas de língua portuguesa”. MATA, 2017. 
que o animismo, ao subverter a autoridade da racionalidade, reescreve "a autoridade da magia nos interstícios do racional/secular/moderno (GARUBA, 2012, p. 243), o teórico destaca um processo de "reencantamento do mundo" que se esboçaria a partir de um tempo que se afasta do "habitual, linear, positivista codificado em noções de progresso e secularização crescente". (GARUBA, 2012, p. 243).

Como uma manifestação artístico-literária do processo de reencantamento do mundo, o realismo animista pode então ser pensado como decorrente de prática linguístico-cultural de "dar uma dimensão concreta a ideias abstratas"(GARUBA, 2012, p. 244) em diferentes formas de organização narrativa nas quais "os ancestrais, espíritos, deuses, são todos fisicamente personificados e animados, atuando em uma dramaturgia de autorreflexão histórica” (GARUBA, 2012, p. 246), próprias de culturas tradicionalmente animistas, como salienta o teórico.

Harry Garuba afirma diferenças entre os conceitos de realismo animista e realismo mágico, mas é possível dizer que o conceito defendido por ele se aproxima do real maravilhoso, de Alejo Carpentier, porque, como o realismo animista, nomeia uma percepção de mundo marcada pelo reencantamento, pela crença em forças vitais que minimizariam o contínuo do mundo. $\mathrm{O}$ famoso prólogo do romance El reino de este mundo, de Carpentier, dá mostras concretas de um processo de produção de sentidos que conclama as muitas faces de uma mesma realidade e que, como o faz Garuba com relação ao realismo animista, insere a autoridade da magia nos interstícios da racionalidade.

Os caminhos abertos para discussão e análise das questões aqui levantadas se desenham ao longo dos textos produzidos pelos integrantes do GEED, muitos deles integrados ao volume que ora apresentamos. Para atendermos aos objetivos da publicação, agrupamos os textos em três partes com o objetivo de explicitar o percurso trilhado pelas pesquisas e produções.

Na primeira parte, intitulada "Realidade, Realismos e Novos Realismos", a questão é discutida em cinco artigos que abordam a relação entre o realismo clássico e os novos realismos; na segunda, "Memória e Tradição", com três produções, reúnem-se textos que têm a memória como elemento de intersecção; na terceira, "Literatura em diálogos", constituída de dois textos, a literatura é posta em diálogo com o cinema e com as artes plásticas.

Apresentado de forma sucinta o objetivo de cada uma das partes que constituem o projeto da publicação, vejamos, de forma também sintética, como cada artigo aborda o tema analisado. O primeiro texto da primeira seção, de autoria de Anna Maria Claus Motta e Roberta Maria Ferreira Alves, tem como título "Entre o ficcional, o real e a história em $\mathrm{O}$ dia das calças roladas, de Germano de Almeida", e se propõe analisar como o romance estabelece uma interessante relação com um fato ocorrido em Cabo Verde, em 1981. As autoras procuram discutir como, pelos entrelaçamentos entre fatos da História de Cabo Verde, memória e ficção, a literatura de Germano Almeida mostra-se como possibilidade de registro do movimento que o homem realiza, na sua historicidade, percorrendo seus anseios e visões de mundo, valendo-se de recursos estéticos que legitimam o fazer literário. Bruna Carla dos Santos e Erinaldo Borges em "Realismo mágico e real maravilhoso: um anseio de afirmação da literatura latino-americano" abordam os conceitos de realismo mágico e real maravilhoso, cunhados por Arturo Uslar Pietri e Alejo 
Carpentier. Os conceitos são discutidos com base em obras literárias significativas, como $\mathbf{O}$ reino deste mundo, de Alejo Carpentier, e Cem anos de Solidão, de Gabriel Garcia Marques. $\mathrm{Na}$ mesma seção, o texto de Eni Alves Rodrigues, "Considerações sobre o realismo animista a partir da leitura do conto 'A morte do velho Kipacaça', de Boaventura Cardoso", reflete sobre o conceito de realismo animista - conceito utilizado por Pepetela (1989) e teorizado por Garuba (2003/2014) e Saraiva (2007). Em seu texto "Realismo afetivo em Predadores", Alice Botelho Peixoto utiliza o operador conceitual desenvolvido por Schøllhammer, "realismo afetivo", para analisar o romance Predadores, de autoria do angolano Pepetela. Para tanto, entende que esse romance manifesta uma forma de economia descritiva, ou de "redução radical do descritivo", como uma evidência de estratégias de elaboração de efeitos sensíveis na linguagem. Natalino da Silva de Oliveira, em "Helena - A angústia do real", discute a percepção de que o real não deveria ser interpretado como algo natural ou como uma realidade adquirida e sólida. $\mathrm{O}$ real, em contexto de subalternidade como o vivenciado por personas sociais retratadas pelo romance Helena, de Machado de Assis, se apresenta como algo a ser conquistado dia após dia, no âmbito das contingências e em pequenos fatos vivenciados por pessoas comuns em suas lutas pela sobrevivência diária. Seguindo essa vertente, o artigo discute elementos do Realismo e suas possíveis roupagens na cena literária criada por Machado de Assis.

Na segunda seção do volume, intitulada "Memória e tradição", Assunção de Maria Sousa e Silva, em "Canto poético no Oká", analisa poemas da poetisa Conceição Lima que circundam as feições da sóya" (conto, lenda), pondo-as em diálogo com os fatos constituintes da história das ilhas de São Tomé e Príncipe, a fim de tratar de conflitos que delineiam o doloroso lugar das pessoas mais velhas acusadas de feiticeiras. Franciane da Conceição Silva, em "A presença da ancestralidade em narrativas de Conceição Evaristo e Mia Couto", discute a função das personagens Ponciá Vivêncio, do romance homônimo, de Conceição Evaristo e Mariamar de As confissões da leoa, de Mia Couto, destacando a questão da ancestralidade e sua forte influência na construção de identidades femininas. Lilian Paula Serra e Deus, em "Relendo as memórias: a questão das memórias em As visitas do Dr. Valdez, de João Paulo Borges Coelho", discute a relação entre a memória individual e a coletiva, na tentativa de demonstrar como a memória percorre o gênero romance, permitindo a retomada de fatos importantes da história de Moçambique, vista pelo viés de histórias singulares.

$\mathrm{Na}$ terceira seção, intitulada "Literatura em Diálogos", Karina de Almeida Calado e Leonardo Domenico Bastos, no artigo "Velhice, pobreza e exclusão social: considerações sobre a postura neorrealista em um conto de Luandino Vieira e em um filme de Vittorio De Sica", valem-se de diálogos entre a literatura e o cinema para analisar a postura neorrealista de Luandino Veira no conto "Vavó Xixi e seu neto Zeca Santos" e de Vittório De Sica no filme Umberto D. Wellington Marçal de Carvalho, no texto. "O novo realismo em Luandino Vieira e Yinka Shonobare", cria um diálogo entre um conto da literatura angolana e criações do artista anglo-nigeriano, para destacar novas tendências realistas surgidas na época atual.

Integra também este volume a tradução do texto "On Animism, Modernity/ Colonialism, and the African Order of Knowledge: Provisional Reflections", de Harry Garuba, feita por Alice Botelho Peixoto. Em português o texto recebeu o título "Reflexões provisórias sobre 


\section{CESPUC \\ 1 O SEMESTRE DE 2018 - N. 32}

animismo, modernidade / colonialismo e a ordem africana do conhecimento". Os trabalhos aqui apresentados evidenciam as discussões e análises feitas ao longo dos anos de existência do GEED, sobretudo com o suporte de articulações e diálogos que a literatura estabelece com várias áreas do conhecimento. Com a intenção de retomar questões postas pelos vários teóricos e estudiosos referidos neste texto, os artigos que compõem o volume especial dos Cadernos Cespuc de Pesquisa retomam os percursos da literatura e das artes de intenção realista, ressaltando suas diferentes feições e as vestes que assumem ao assumir novos arranjos estéticos em que a temática realista é, ao mesmo tempo, revisitada e posta em questão.

\section{REFERÊNCIAS}

CARPENTIER, Alejo. Dos novelas: El reino de este mundo: El Acoso. Caracas: El Nacional, 1948. p. 12 - 122.

CARPENTIER, Alejo. O reino deste mundo. Tradução de João Olavo Saldanha. Rio de Janeiro: Ed. Civilização Brasileira, 1985.

CHIAMPI, Irlemar. O realismo maravilhoso. São Paulo: Editora Perspectiva, 1980.

FIGUEIREDO, Vera Lúcia Follain de. Novos realismos, novos ilusionismos. In: MARGATO, Izabel; GOMES, Renato Cordeiro (Orgs.). Novos realismos. Belo Horizonte: Editora UFMG, 2012. p. $119-132$.

GARUBA, Harry; Elisangela Tarouco. Explorações no realismo animista: notas sobre a leitura e a escrita da literatura, cultura e sociedade africana. Tradução de Elisângela Nonada. Letras em revista, ano 15, n. 19. p. $235-256,2012$.

JAMES, C.L.R. Os jacobinos negros - Toussaint Louverture e a revolução de São Domingos. São Paulo: Editorial Boitempo, 2000.

MATA, Inocência. A condição pós-colonial das literaturas africanas de língua portuguesa: algumas diferenças e convergências e muitos lugares-comuns. In: LEÃO, Ângela Vaz (Org.). Contatos e ressonâncias: literaturas africanas de língua portuguesa. Belo Horizonte: PUC Minas, 2003. p.43-72.

MATA, Inocência. O pós-colonial nas literaturas africanas de língua portuguesa. Disponível em: < http://bibliotecavirtual.clacso.org.ar/ar/libros/aladaa/mata.rtf.>. Acesso em: 13 out. 2017.

PELLEGRINI, Tânia. Realismos: modos de usar. Estudos de Literatura Brasileira Contemporânea. Brasília, n.39, p. 11-17, jan. / jun. 2012.

PEPETELA, Lueji (O nascimento dum império). Luanda: UEA, 1989. Disponível em: < http:// dx.doi.org/10.1590/S2316-40182012000100001 > Acesso em: 16 jan. 2017. 
PIETRI, Arturo Uslar. El cuento venezolano. In: PIETRI, Arturo Uslar. Letras y hombres de Venezuela, 3. ed. Madrid: Editorial Mediterrâneo, 1974.

SARAIVA, Sueli. O realismo animista e o espaço não-nostágico em narrativas africanas de língua portuguesa. Anais Encontro Regional da ABRALIC, 2007.

SCHØLLHAMMER, Karl Eric. As imagens do realismo mágico. Gragoatá, Niteroi, n. 16, p. 117-132, 1. sem. 2004. Disponível em: < http://gragoata.uff.br/index.php/gragoata/article/ viewFile/579/444 > . Acesso em 10/02/2107.

SCHØLLHAMMER, Karl Eric. Além do visível: o olhar da literatura. Rio de Janeiro: 7 Letras, 2007. 